\title{
User-Related Issues in Design and Use of Smartgrids Seen as Complex Sociotechnical Systems: Example of the VERTPOM Project
}

\author{
Emilie Loup-Escande ${ }^{1}$, Sophie Capo ${ }^{1} \&$ Helios Raharison ${ }^{1}$ \\ ${ }^{1}$ CRP-CPO UR UPJV 7273, Université de Picardie Jules Verne, Chemin du Thil, Amiens, France \\ Correspondence: Emilie Loup-Escande, CRP-CPO UR UPJV 7273, Université de Picardie Jules Verne, Chemin \\ du Thil, 80000 Amiens, France. Tel: 33-3-2282-8912. E-mail: emilie.loup-escande@u-picardie.fr
}

Received: April 28, 2020

doi:10.5539/jsd.v13n4p76
Accepted: June 12, $2020 \quad$ Online Published: July 29, 2020

URL: https://doi.org/10.5539/jsd.v13n4p76

\begin{abstract}
The impact of human activities on the environment is no longer to be demonstrated today and concerns many fields. With a view to environmental protection, applied to global warming limitation and fossil fuels preservation, Smartgrids are currently emerging, especially, under the impetus of European and French legislation. In emerging technologies, end-user-related issues, articulated with the design process, continue to raise conceptual, methodological and operational questions. The perspective of complex sociotechnical systems is useful for Smartgrids and to underline the necessary multidisciplinary approach to design. Yet raised for decades, the articulation of multidisciplinary approaches in the design of complex systems still questions fundamental problems today. These questions are all more unresolved in the context of innovative technologies such as Smartgrids. The objective of this paper is to propose 1) a conceptual reflection applied to the design of these Smartgrids seen as emerging sociotechnical systems, and 2) a case study by illustrating with the VERTPOM project. On the one hand, we discuss four fundamental points in user-centered design of Smartgrids: we describe the legislative impulses for the rollout of smart metters and the emergence of Smartgrids, we highlight the supplier/consumer synergy that is essential for efficient energy management, we explain the importance of adapting systems to the wide public in domestic, professional and public situations in the context of consumer control of energy demand, and we address the issue of the more traditional field of supervision and control of complex dynamic processes by operators. On the other hand, we present the VERTPOM project aiming at developing a set of digital tools for energy management and energy efficiency in order to make a positive energy territory that produces more energy than it consumes by introducing the project and its actors and explaining how design acceptable Smartgrids for consumers and operators of energy suppliers.
\end{abstract}

Keywords: Smartgrids, artificial intelligence, complex sociotechnical system, ergonomics

\section{Introduction}

Defining the multidimensional concept of emerging technologies is useful for addressing design issues and future uses. For a decade, the concept of emerging technology, also qualified of new technologies advanced or innovative technologies has been used without being specifically defined. Loup-Escande (2019) uses four characteristics to distinguish emerging technologies from other more classic or older technologies : 1) a major technological innovation - technological, hardware, software or on the nature and processing of data, as in artificial intelligence; 2) a priori fuzzy uses - initially driven by technocentric issues rather by operational applications, which are going to evolve with time, in interaction with evolution of technologies, of uses and users and the emergence of new application areas; 3) limits to wide application - due to at least five types of limits: technological; usability; immature applicability; lack of reporting feedbacks; and methodological limits for identifying their operational potentials; 4) the perspective and the hope of an economic and social evolution generated in their context of use.

According to the Energy Regulation Commission, Smartgrids are public electricity networks which have the specificity to benefit from functionalities stemming from new information and communication technologies. Their scope is to ensure balance and sustainability between the supply and demand for electricity and provide a secure, sustainable and competitive supply to consumers. They become communicative and aim, considering the actions of the actors of the system, to ensure a more efficient, economically viable and secure delivery of electricity. Piloting allows the management of constraints, for example those linked to the intermittency of renewable energies and the integration of new uses such as the electric vehicle. Nearer to real-time management tends to allow a 
balance between consumption and production. The control of energy demand results from the control of consumption. The consumer tends to become an actor in the system. Smart-grids differ from 'Smart meters', or communicating meters, this is a larger system implemented on an all territory. Smart-grids integrate the techniques of artificial intelligence, through large databases (Big Data).

So, based on a state of the art, the four dimensions characterizing emerging technologies are actually involved. Firstly, major technological innovation induced by the addition of information and communication technologies to existing electrical networks combined with the potential of large databases and artificial intelligence (Moustafa \& Fréjus, 2010). Secondly, the equally emerging literature clearly demonstrates the barriers to conceptualize and facilitate effective behaviors, linked to the use of Smartgrids to foster the control of energy consumption and maintain it over time (Chauvin, Rauffet, Tréhin, Berruet \& Lassalle, 2015; Guibourdenche, Vacherand-Revel, Fréjus \& Haradji, 2015). The state of the art on this subject also allows to note the predominance of techno-centered publications, and more recent evolution to research applied to user-centered view point (Fréjus, 2019). Thirdly, limits of consumer use of Smartgrids, identified by pioneering researches. Faces technical issues searches were carried out before effective Smartgrids deployment, which was still inoperative at least partially and with breakdowns. Limits implied by a weak usability appears to be a recurring obstacle in the use of Smartgrids. Specifically, concerning the gap between web interfaces and consumer characteristics; access difficulties, characteristics of interfaces, languages and symbols used, and the need of consumption diagnosis and finding solutions for improvement (Lassalle, Amelot, Chauvin \& Boutet-Diéye, 2016). Fourth, smart grids, applied to environmental protection, foster the control of energy demand and the use of renewable energies and mainly aim to limit global warming and reducing our reliance on fossil fuels. Changing energy consumption behavior seems to be the preferred solution to curb global warming. Indeed, Smartgrids meet legislative and environmental requirements and are integrated into a complex sociotechnical system.

Consequently, and as other emerging technologies, Smartgrids are questioning about user-related issues in design and use. In the rest of the article, we deal with the legislative impulses for the emergence of Smartgrids, the supplier/consumer synergy for efficient energy management, adapting systems to consumers (those related to the control of energy demand) and operators (those related to the supervision and control of complex dynamic processes). After this theoretical conceptualization, we illustrate how we deal with user-related issues in design and use, basing on the VERTPOM case study.

\section{Users-Related Issues of Smart Grids, a Complex Sociotechnical System}

We propose a conceptual framework of Smartgrids as complex sociotechnical systems by focusing on users-related issues. So, we deal with the legislative impulses for the emergence of Smartgrids, the supplier/consumer synergy for efficient energy management, adapting systems to consumers (those related to the control of energy demand) and operators (those related to the supervision and control of complex dynamic processes).

\subsection{Sociotechnical Systems}

Appeared in the 50s, different definitions of "sociotechnical systems" can meet, and several models have been proposed. A sociotechnical system can be defined as "a set of human and technical units organized and interacting dynamically for the achievement of a common objective" (Amalberti \& Mosneron-Dupin, 1997, p. 127). It is composed of interconnected technical, psychological and social elements that have a common objective. "The boundary between the system and its environment is specified by the analyst, and isn't inherent in the system" (Vicente, 1999, p. 9). From a systemic point of view, the "man-machine system" and no longer its components taken in isolation, aimed to study "performance" resulting from their interactions (de Montmollin, 1995). The complex systems approached as sociotechnical systems demonstrate the strong interaction of human, technical and organizational components (Baxter \& Somerville, 2011). The organizational perspective is subject to increasingly rapid technological developments and to a highly competitive and dynamic global economic context (Sperandio, 1996; Vicente, 1999; Rasmussen, 1997, 2000; Rasmussen \& Svedung, 2000). A vertically oriented perspective highlights these environmental pressures and the needs of disciplinary contributions and especially the need for their articulation according to organizational levels (Figure 1). 


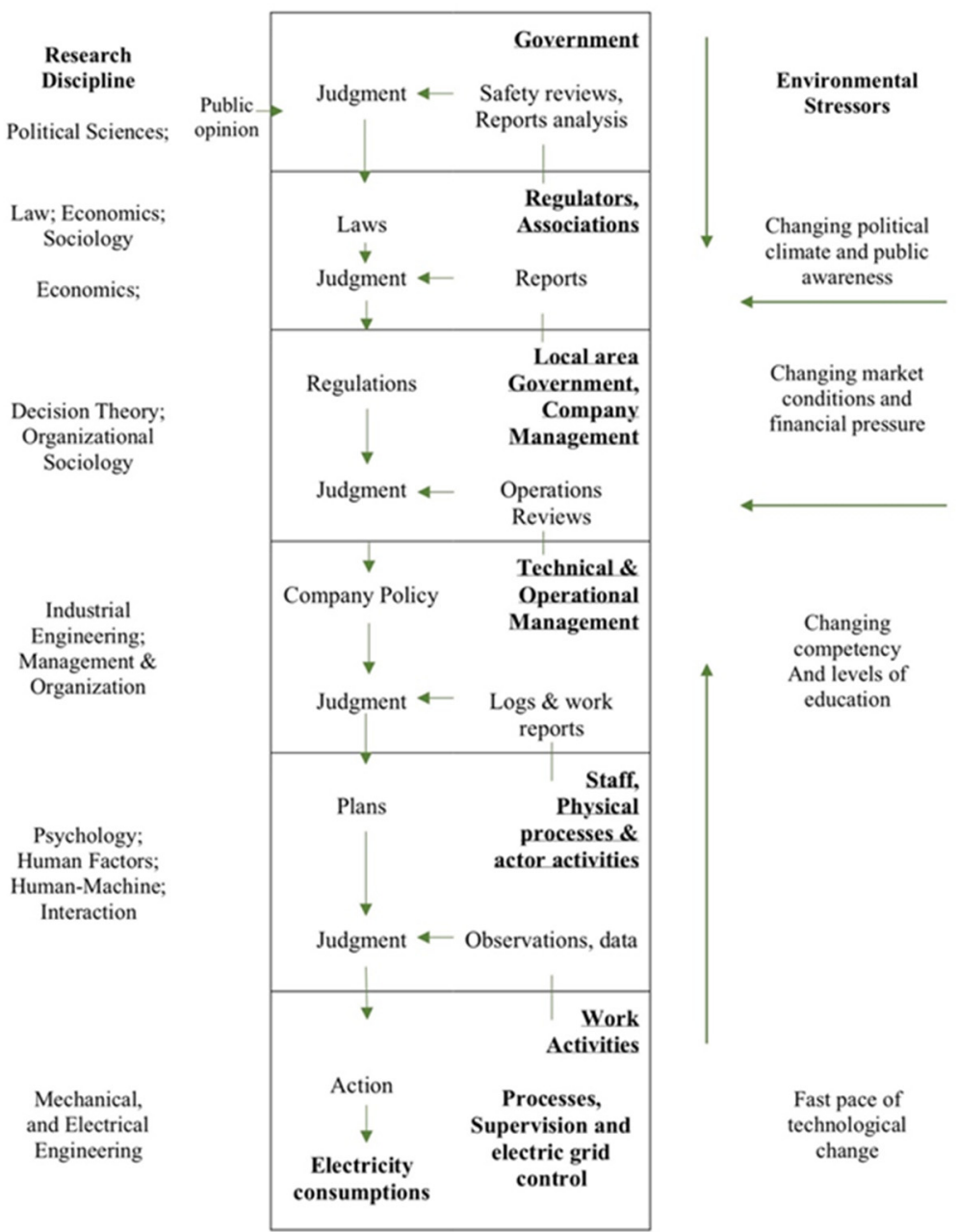

Figure 1. A complex sociotechnical system in a vertically oriented perspective

Note. In a dynamic society, the system is subject to environmental pressure and levels are usually studied separately by the different academic disciplines. There is a need to articulate the different disciplines contributions to consider the interactions between the knowledge at all levels, from the work and activities level to the top levels (inspired from Rasmussen, 2000).

The functioning of a complex sociotechnical system and its results go beyond the description of its technological, human and organizational components. Achieving objectives is part of the implementation of the functions that compose it and their interactions. These interactions are subject to the internal and external conditions of human, technological and organizational elements (Hollnagel, 1998). Also, these interactions are also part of the diachronic perspective of the evolution and adaptation of the system; economic, ecological, legislative constraints, human learning and evolution and adaptation of artificial intelligence, evolution of populations, technological devices, demography, etc.

\subsection{Smartgrids Are Emerging Complex Sociotechnical Systems}

In front of the consequences of human activities on the environment, including climate changes and depletion of fossil fuels, legislative and regulatory levels introduced the smart meters and the deployment of Smartgrids as solution. These technological solutions involve local energy distribution networks and their actors, with the managers of the local energy distribution networks, the energy suppliers of traditional and renewable energies, but also consumers, communities and public spaces. For that, Smartgrids mobilize emerging and complex technologies such as AI and Big Data to assist the user in the control of energy demand, and involve, for suppliers, complex interfaces with regard to supervision and control of dynamic processes.

In this sense, we can consider Smartgrids as complex sociotechnical systems as defined by Rasmussen (2000). Concerning the user-related issues in design and use, we address (Figure 2): 
- "Government" and "Regulators, associations" levels through the "Legislatives impulses for the deployment of smart meters and the emergence of Smartgrids";

- "Local area government, company management" levels in terms of "Energy management through supplier/consumer synergy";

- "Staff, physical processes \& actor activities" level from the perspective of "Control of energy demand seen as a consumer activity";

- "Work activities" level as "supervision and control of complex dynamic processes".

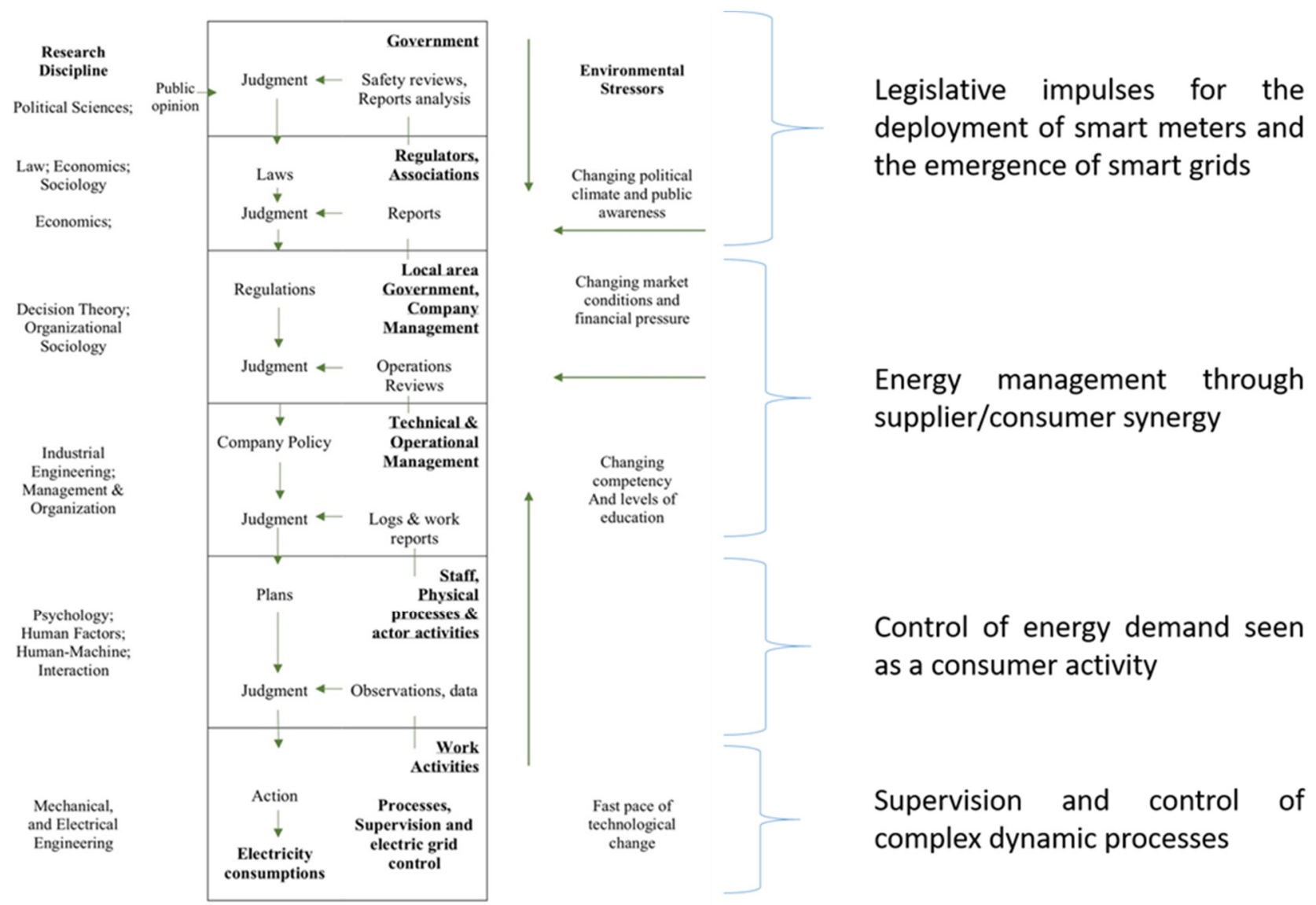

Figure 2. The four user-related issues in design and use of Smartgrids seen as complex sociotechnical systems

\subsection{Legislative Impulses for the Deployment of Smart Meters and the Emergence of Smartgrids}

Since the 1980s, the third industrial revolution initiated its genesis, in response to climate change and energy constraints and demands (Rifkin, 2012). This technological, but also energy and social revolution invites to rethink globally and locally the production of storage and consumption of energies patterns. The conjunction of these three revolutions leads to the creation of "intelligent networks". In Europe, the implementation of smart meters is initiated by Directive 2009/72 / ce of the European Parliament and of the Council of July 13, 2009, concerning common rules for the internal market in electricity. These smart meters constitute the fundamental technological building block for consumer participation in the electricity supply market. Member states set a calendar over 10 years maximum to equip $80 \%$ of customers by 2020 . In France, the law, ${ }^{\circ} 2015-992$ of August 17, 2015, relating to the energy transition for green growth, targets a socially inclusive mode of a low-energy/ressources/carbon economic development supporting the innovation and competitiveness of companies. This law encourages States, local authorities, businesses, associations and citizens to contribute to the development of positive energy territories: enabling a balance to be achieved between energy consumption and production at the local level by reducing energy demand. It targets a positive energy territory, by energy efficiency, the reduction of greenhouse gas emissions and the reduction of consumption of fossil fuels, and aims to deploy renewable energies. In France, Law No. 2010-1488 of December 7, 2010, relating to the new organization of the electricity market, specifies that 
consumers have free access to their consumption data. The decree $n{ }^{\circ} 2017-948$ of May 10, 2017, relating to the methods of providing consumers with electricity and gas consumption data, specifies that the managers of public electricity and natural gas distribution networks make available, in a secure area of its website, their metering data to consumers, as well as alert systems on the level of consumption, and local and national consumption comparison elements present, at a minimum, the daily and monthly consumption indexes. So, the legislative conditions for the introduction of Smartgrids were in place.

\subsection{Energy Management through Supplier/Consumer Synergy}

To optimize the energy management and the energy efficiency of a territory, the Smartgrids use traditional and renewable energies and manage these different energy sources more effectively, balancing and anticipating fluctuations in production and consumption, and using the processing of large databases, collected via smart meters in an energy bank. This is provided by consumers' data who control energy demand, and must be managed by suppliers, in particular the operators, with supervision and process control interfaces of the energy bank (Capo \& Loup-Escande, 2019).

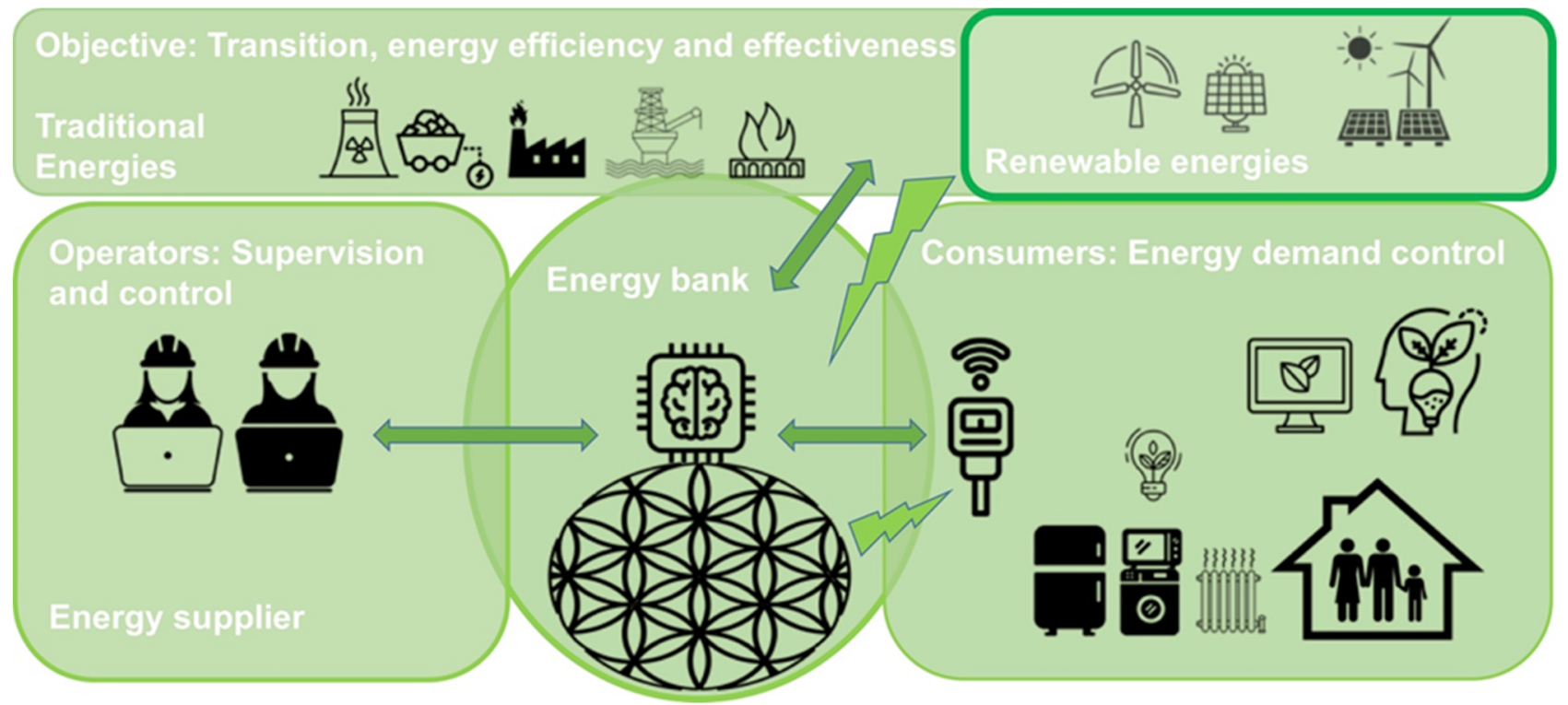

Figure 3. Energy efficiency due to a synergy between suppliers who supervise and control the energy bank and consumers who control their energy demand

\subsection{Control of Energy Demand Seen as a Consumer Activity}

\subsubsection{Usefulness and Usability of Smartgrids, the Two Main Levers of the Control of Energy Demand}

Usefulness and usability are central in the user-centered design of emerging technologies. Usefulness is defined as the adequacy of the technology with the needs of the user, that is to say the property of the technology which results from the effective consideration or not of the needs of the users (Loup-Escande, Burkhardt \& Richir, 2013). Usability is the result of user-technology interaction. It refers to the fact that a technology must be able to be used effectively, efficiently and satisfactorily in a context of specified use (ISO 9241-11: 2018).

Usefulness and usability of Smartgrids are the main levers of the control of energy demand for two reasons. Firstly, consumers' interfaces impact the control activity of energy demand (Guibourdenche et al., 2015). Indeed, Smartgrids providing consumers with real-time information on their consumption are profoundly changing the activity of energy consumption control (Lassalle et al., 2016). So, research is looking at the brakes and levers of alternative energies mobilized in these Smartgrids (e.g., Perlaviciute \& Steg, 2014), or seeking to adapt models of social acceptability - determinated by perceived usefulness and usability - to the Smartgrids (e.g., Toft, Schuitema \& Thøgersen, 2014).

Secondly, the presentation of eco-feedbacks by information and communication technologies to consumers on their actual energy consumption will allow them to generate eco-responsible behavior in order to reduce their energy consumption (Bastien, 2012; Lassalle, Amelot, Chauvin \& Boutet-Diéye, 2016; Fleury, Jamet, Michinov, Michinov \& Erhel, 2018; Fréjus, 2019). In other words, if the interfaces meet user needs (e.g., present the evolution of consumption over time, situate this ratio in relation to the average electricity consumption of similar households) 
and are easy to use, consumers will have access to the information they need to understand energy control, leading to the adoption of eco-responsible behavior (Chauvin, Rauffet, Tréhin, Berruet \& Lassalle, 2015).

These interfaces must be useful, usable and then accepted by the wide public, in domestic, professional and public situations, and they must be adapted to the characteristics of a wide range of users in terms of age, profession, technophilia or sensitivity to ecology.

\subsubsection{Pervasive and Symbiotic Technologies to Promote the Development of Eco-Behaviours}

Smartgrids are pervasives and symbiotics technologies. Pervasive technologies are minimally intrusive devices that are based in the living environment and on which the user no longer has to act (Bobillier-Chaumon, Cuvillier, Durif-Bruckert, Cros, Vanhille \& Bekkadja, 2014). It is the technology that anticipates needs by continuously exploiting environmental data in order to propose adequate solutions to the user. These technologies are Humans "techno-symbiotes", i.e. technologies likely to induce a progressive dependence on humans and with which the latter develop a reciprocal link of influence (Brangier, Hammes-Adelé, \& Bastien, 2009) capable of amplifying intelligence, simplifying certain tasks or producing emotions in users.

The user-centred design of these pervasive and symbiotic technologies requires the use of prospective ergonomics, which consists of anticipating or building future needs and uses with a view to designing technologies that are as user-friendly as possible (Robert \& Brangier, 2009). For that, "Prospective ergonomics needs creative excitement to generate new ideas about the needs to be met and the artifacts to be created" (Brangier \& Robert, 2014, p. 10). Thanks to these creative methods, it is possible to imagine or even co-create eco-behaviours and to anticipate the functionalities to be implemented in consumer interfaces.

\subsection{Supervision and Control of Complex Dynamic Processes}

Smartgrids are complex and dynamic systems. Indeed, it is a complex system with three characteristics: 1) it is composed of many elements interacting with each other often in an automated way, 2) these elements have an overall behaviour that cannot be explained from each of these individual elements, 3 ) in this complex system, one dysfunction leads to another, and the consequences of these dysfunctions are not predictable (Sperandio, 1988). It is also a system that evolves in dynamic situations in which the object of the activity is transformed independently of the operator's activity (Hoc, 2004): e.g. optimised control of energy demand in the territory depends not only on the operator's actions exercised via the supervision tool in terms of energy source allocation, but also on the energy-consuming activities deployed by consumers.

These two characteristics (complex and dynamic systems) lead the operator to control and supervision tasks that are highly demanding in terms of cognitive resources (information detection process in rich interfaces, problem solving strategies and decision making adapted to the different actors of the Smartgrids). In order to design supervision tools adapted to the activity and the cognitive resources of the operators, it is essential to involve them from the early stages of design.

\section{Addressing Users-Related Issues in the VERTPOM Project}

After prensenting the objective of the VERTPOM project, scope and project's actors, we explain how ergonomics contributes to design acceptable Smartgrids both for consumers and operators of energy suppliers. According to the International Ergonomics Association (2000), ergonomics (or human factors) is "the scientific discipline concerned with the understanding of interactions among humans and other elements of a system, and the profession that applies theory, principles, data, and other methods to design in order to optimize human well-being and overall system performance".

\subsection{Objectives}

Started in june 2017, VERTPOM (True Energy of the Territorial POsitive and Modular) follows the experience in Picardy of a multi fluid site (electricity, gas and water). The aim of the project is to facilitate the use of renewable energies specific to each territory, in order to contribute to the reduction of greenhouse gases and make the territories less dependent on traditional energies, while at the same time becoming Positive Energy Territories, producing more energy than they consume. The "Energy Bank", a central concept of this project, is a software solution based on a simulator and artificial intelligence algorithms. This Big Data solution manage the entire production and consumption cycle of a territory. This is part of the design of a complete sociotechnical system, combining Artificial Intelligence in articulation with related disciplines from a multidisciplinary perspective, with contributions of disciplines related to Innovative Technologies, Electrical Energy and Associated Systems, Intelligent Systems, Applied Fundamental Mathematics, Applied Analysis, Information and Systems Modeling, sociology and, in the scope of this paper: Ergonomics. These disciplines are represented by 9 research teams included in 6 laboratories. 
Focusing on the sociocultural dimensions of the territory involves consumers throughout the design project, making them "actors" of the energy transition issues. The ergonomic contributions introduce the point of view of energy consumers, as well as the issues related to the supervision and management of the energy network in the design cycle.

These contributions have two purposes, on the one hand, to go beyond the current findings of the acceptability of innovative systems in the control of energy consumption, and on the other hand, to enrich the specification of the device of supervision of the intelligent electric network by the technology from the field of human-machine interactions in the management of complete dynamic processes.

\subsection{Scope and Project Actor's}

Within the framework of the evolution of European directives, and the French energy law, VERTPOM introduce innovative smart metering, in association with artificial intelligence. This multifluid, consumption and production network includes electricity, water, gas, and renewable energies.

A simulator allows analysis of control and supervision of the global smart grid. The VERTPOM partners are CIAC International Technologies (project leader), Gazelec de Peronne (Energy Network Manager), Ville de Péronne (case study field) and University de Picardie Jules Verne represented by six research laboratories (Figure 4).

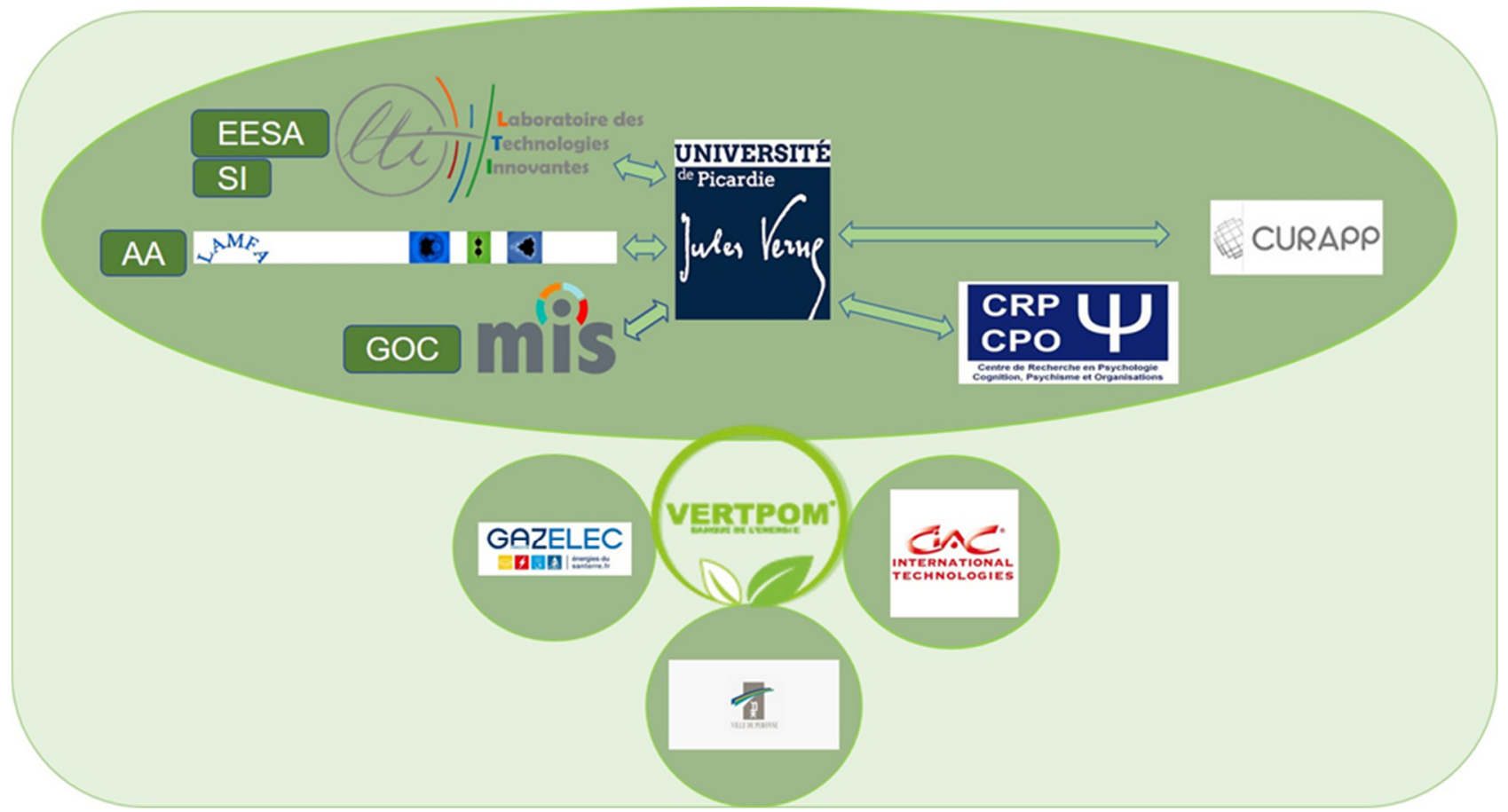

Figure 4. VERTPOM project actor's

Note. LTI: Laboratory of Innovative Technologies; EESA: Electrical Energy and Associated Systems; IS: Intelligent Systems; LAMFA: Amiens Laboratory of Applied Fundamental Mathematics; AA: Applied Analysis Applied Analysis Team (A^ 3); MIS: Information and Systems Modeling; GOC: Team (Graphs, Optimization and Constraints); CRP-CPO: The Research Center in Psychology: Cognition, Psychism and Organizations (EA7273); CURAPP: University Center for Administrative and Political Research in Picardy.

\subsection{Ergonomics' Contribution to Design Acceptable Smartgrids for Consumers}

The contribution of ergonomics here is to conduct evaluations of consumer interfaces - respecting the legislative aspects of consent - in order to perfect their design on the one hand, and to study the effects of these emerging technologies on the activity related to the control of energy demand within the framework of domestic activities on the other hand (e.g., Guibourdenche et al., 2015). Indeed, Smartgrids providing consumers with real-time consumption information, via in the private internet portal and intelligent multi-fluid iBoxes in VERTPOM project, modify the activity of energy consumption control (Lassalle et al., 2016).

In the VERTPOM project, we respond to these two objectives by articulating three complementary methods. Firstly, user-centred design - as defined in ISO 9241-210: 2019 - allows the evolutive property of usefulness and usability 
to be considered by integrating users at several steps of the design process (Muller, Haslwanter \& Dayton, 1997; Reich, Konda, Monarch, Levy \& Subrahmanian, 1996). Secondly, the personas method (which are fictitious and stereotyped characters with characteristics close to the target users) seen as a method of creativity by designers would allow us to access numerous, original and operational ideas from the point of view of the design of the functionalities and properties of the HMIs (Brangier, Bornet, Bastien \& Vivian, 2012). Thirdly, the extraordinary users' method would allow us to discover or generate needs "covering" those of the large panel of consumers (individuals, industrials, public institutions) targeted by the project and variable in terms of age, socio-professional categories and degree of technophilia necessarily impacting the use of these emerging technologies. Thus, we would be able to implement in HMIs a wide spectrum of needs that standard users are not or hardly aware of, particularly numerous and diversified in the field of Smartgrids (Lassalle, 2019).

\subsection{Ergonomics' Contribution to Design Acceptable Smartgrids for Suppliers}

In the Vertpom project, the operators of the energy suppliers will use a supervision tool aimed at predicting and managing peaks in energy demand in the local network in relation to the global network and the energy sources mobilised. It is a complex, dynamic, highly automated and distributed system (Sperandio, 1988). In dynamic situations, the object of the operator's activity is transformed independently of the operator's activity, even if this activity can influence this transformation. Our goal is to guarantee an optimal operator-system coupling (Amalberti, 1996; Hollnagel, 1998).

To achieve this, two complementary approaches will be mobilized. The first is ergonomic inspection, which is an evaluation approach based on criteria, such as those proposed by Bastien \& Scapin (1993) for the evaluation of computer devices. This method is generally used to discover and correct design problems before conducting user tests (Bastien \& Scapin, 1993). The result of such an assessment is a series of recommendations based on the representation of a third party who is not the end user. For this reason, further user testing is required.

The second approach is the evaluation of the tool through user testing. The evaluation of prototypes is a simulation method in the sense of an artificial reproduction of a phenomenon to be studied, specifically aimed at reconstructing a work or use situation in order to observe and induce behaviors close to those likely to appear in a real future situation. Simulation techniques are part of an approach to the design of innovative technologies based on prototyping (Dow, Heddleston \& Klemmer, 2009). User-centred evaluation of prototypes usually involves user testing, which is a method used to evaluate technological devices with end-users by studying the behavior of endusers (Baccino, Bellino \& Colombi, 2004). This method has three advantages for the design of emerging technologies such as Smartgrids. Firstly, it is a full-scale simulation that will allow users to compare the "invariants" that guide their activity with the circumstances associated with the project under development (Bobillier-Chaumon, Rouat, Laneyrie \& Cuvillier, 2018). By observing the actual impacts of technology on user activities, it is possible to identify the conditions that will enable users to get real benefit from their use (Burkhardt $\&$ Lubart, 2010). On the other hand, the prototypes evaluated through user tests provide support in understanding unclear technological concepts for participants who do not have sufficient technological expertise, such as future users. They help users to develop the conceptualizations they need to discuss with designers (Anastassova, Mégard $\&$ Burkhardt, 2007). Finally, prototypes are also a means of projecting users into a future use context incorporating the technology being designed. Users are then able to propose features and properties of the future application that were previously latent and unconscious, and thus contribute to enriching practical acceptability by integrating these new needs during design (Newell, Carmichael, Morgan \& Dickinson, 2006).

\section{Conclusion}

The objective of this positioning paper was to show that the design of Smartgrids did not only involve the resolution of technological issues, but also questioned the human and social sciences, particularly ergonomics. To do so, we argued how Smartgrids were complex socio-technical systems and posed four user-related issues in design and use. These are legislatives aspects relating to consumption data and control of energy demand seen as a new consumer activity on the one hand, and energy management and control through complex supervision tool used by suppliers on the other hand. Based on the VERTPOM project, we then explained how ergonomics could address - with its theoretical concepts and methodological tools - problems related to consumers and those associated with energy suppliers. In future work, we will implement the suggested and argued approach, and thus propose a feedback on the design of Smartgrids that are acceptable to both consumers and suppliers.

\section{Acknowledgments}

VERTPOM project supported by the Investments for the Future Programme managed by ADEME (French Agency for the Environment and Energy Management). 


\section{References}

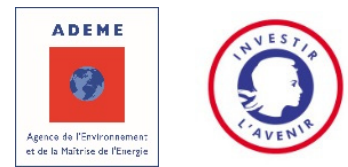

Amalberti, R. (1996). La conduite de systèmes à risques. Le Travail Humain. Paris, France: PUF.

Amalberti, R., \& Mosneron-Dupin, F. (1997). Facteurs humains et fiabilité, quelles démarches pratiques? Toulouse, France: Octarès.

Anastassova, M., Mégard, C., \& Burkhardt, J.-M. (2007). Prototype Evaluation and User-Needs Analysis in the Early Design of Emerging Technologies. In J. A. Jacko (Ed.), Human-Computer Interaction. Interaction Design and Usability. HCI 2007. Lecture Notes in Computer Science, 4550 (pp. 383-392). Berlin, Allemagne: Springer Heidelberg. https://doi.org/10.1007/978-3-540-73105-4_42

Baccino, T., Bellino, C., \& Colombi, T. (2004). Mesure de l'utilisabilité des interfaces. Paris, France: Hermes Science Publications.

Bastien, J. M. C. (2012). Global Warming: Possible Contributions from Cognitive Ergonomics and HumanComputer Interaction to the Reduction of Energy Consumption (in French). Le Travail Humain, 3(75), 329348. https://doi.org/10.3917/th.753.0329

Bastien, J. M. C., \& Scapin, D. L. (1993). Ergonomic Criteria for the Evaluation ofHuman-Computer Interfaces: Technical report 156, May 1993. Programme 3 Artificial intelligence, cognitive systems, and man-machine interaction.

Baxter, G., \& Sommerville, I. (2011). Socio-technical systems: From design methods to systems engineering. Interacting with Computers, 23(1), 4-17. https://doi.org/10.1016/j.intcom.2010.07.003

Bobillier-Chaumon, M.-E., Cuvillier, B., Durif-Bruckert, C., Cros, F., Van-hille, M., \& Bekkadja, S. (2014). Designing a Pervasive Technology Environment for Home Care of Elderly: a Prospective Approach by Activity Systems (in French). Le Travail Humain, 77(1), 39-62. https://doi.org/10.3917/th.771.0039

Bobillier-Chaumon, M.-É., Rouat, S., Laneyrie, E., \& Cuvillier, B. (2018). De l'activité DE simulation à l'activité EN simulation : Simuler pour stimuler. Activités, 15, 15-1. https://doi.org/10.4000/activites.3136

Brangier, E., \& Robert, J.-M. (2014). L'ergonomie prospective : Fondements et enjeux. Le Travail Humain, 77(1), 1-20. https://doi.org/10.3917/th.771.0001

Brangier, E., Bornet, C., Bastien, J. M. C., \& Vivian, R. (2012). Assessing Personas' Capacity to Help the Ideation Process in a Digital Library Design (in French). Le Travail Humain, 75(2), 121 - 145. https://doi.org/10.3917/th.752.0121

Brangier, É., Hammes-Adelé, S., \& Bastien, J.-M. C. (2010). Critical analysis of technology acceptance approaches: From usability to human-technology-organization symbiosis (in French). European Review of Applied Psychology, 60(2), 129-146. https://doi.org/10.1016/j.erap.2009.11.002

Burkhardt, J.-M., \& Lubart, T. (2010). Creativity in the Age of Emerging Technology : Some Issues and Perspectives in 2010. Creativity and Innovation Management, 19(2), 160-166. https://doi.org/10.1111/j.14678691.2010.00559.x

Capo, S., \& Loup-Escande, E. (2019). Effet des Smartgrids sur la transition énergétique: exemple de VERTPOM. Journées Internationales de Psychologie à Amiens, 14-15.

Chauvin, C., Rauffet, P., Tréhin, Berruet, P., \& Lassalle, J. (2015). Using Cognitive Work Analysis to design smart grid interfaces. Human Factors User Experience in everyday life, medicine, and work, Human Factors and Ergonomics Society Europe, Oct 2015, Groningen, Netherlands. hal-01337564

de Montmollin, M. (1995). Systèmes homme - machine. In M. de Montmollin (Ed.), Vocabulaire de l'ergonomie, $2 e$ édition revue et augmentée (pp. 264). Toulouse, France : Octarès.

Dow, S. P., Heddleston, K., \& Klemmer, S. R. (2009). The Efficacy of Prototyping under Time Constraints. Proceedings of the Seventh ACM Conference on Creativity and Cognition. Berkeley, California, USA. https://doi.org/10.1145/1640233.1640260

Fleury, S., Jamet, E., Michinov, E. Michinov, N., \& Erhel, S. (2018). A priori acceptability of various types of digital display feedback on electricity consumption. Le Travail Humain, 3(81), 247-267. 
https://doi.org/10.3917/th.813.0247

Fréjus, M. (2019). Expansion and renewal of the issues dealt with by ergonomics in the field of sustainable development: A 12-years review of researches on household activities and energy consumption management (in French). Psychologie Française, 64(2), 179-196. https://doi.org/10.1016/j.psfr.2018.07.002

Guibourdenche, J., Vacherand-Revel, J., Fréjus, M., \& Haradji, Y. (2015). Analysis of domestic activity contexts for the design of ubiquitous energy-efficient systems (in French). Activités, 12(1), 46-69. Retrieved from http://www.activites.org/v12n1/v12n1.pdf

Hoc, J. (2004). 31. La gestion de situation dynamique. In Ergonomie (pp. 515-530). Paris, France: PUF. https://doi.org/10.3917/puf.falzo.2004.01.0515

Hollnagel, E. (1998). Cognitive Reliability and Error Analysis Method (CREAM). Elsevier Science.

Lassalle, J., Amelot, A., Chauvin, C., \& Boutet-Diéye, A. (2016). From the artifact to the instrument to manage electricity consumption: ergo-sociological approach to the instrumental genesis of smart grids (in French). Activités, 13(2). https://doi.org/10.4000/activites.2875

Loup-Escande, E. (2019). Concevoir des technologies émergentes acceptables : complémentarité des approches expérimentale, écologique et prospective. Habilitation à Diriger des Recherches en Ergonomie. Université de Picardie Jules Verne, Amiens, France.

Loup-Escande, E., \& Burkhardt, J.-M. (2019). Anticipating and Evaluating the Usefulness of Emerging Technologies in Ergonomic Design: a Review of Usefulness in Design (in French). Activités, 16(2).

Loup-Escande, É., Burkhardt, J.-M., \& Richir, S. (2013). Anticipating and Evaluating the Usefulness of Emerging Technologies in Ergonomic Design: a Review of Usefulness in Design (in French). Le Travail Humain, 76(1), 27-55. https://doi.org/10.3917/th.761.0027

Moustafa, \& Fréjus. (2010). Ergonomie des situations domestiques : nouveaux défis, nouvelles opportunités. In Valléry, G., Le Port, M. C., \& Zouinar, M. (Eds.), Ergonomie, conception de produits et services médiatisés (pp. 211-240). Paris, France : PUF. https://doi.org/10.3917/puf.lepo.2010.01.0211

Muller, M. J., Haslwanter, J. H., \& Dayton, T. (1997). Chapter 11-Participatory Practices in the Software Lifecycle. In M. G. Helander, T. K. Landauer, \& P. V. Prabhu (Eds.), Handbook of Human-Computer Interaction (pp. 255-297). https://doi.org/10.1016/B978-044481862-1.50077-7

Newell, A. F., Carmichael, A., Morgan, M., \& Dickinson, A. (2006). The use of theatre in requirements gathering and usability studies. Interacting with Computers, 18(5), 996-1011. https://doi.org/10.1016/j.intcom.2006.05.003

Perlaviciute, G., \& Steg, L. (2014). Contextual and psychological factors shaping evaluations and acceptability of energy alternatives : Integrated review and research agenda. Renewable and Sustainable Energy Reviews, 35, 361-381. https://doi.org/10.1016/j.rser.2014.04.003

Rasmussen, J. (1997). Risk management in a dynamic society: a modelling problem. Safety Science, 27(2-3), 183213. https://doi.org/10.1016/S0925-7535(97)00052-0

Rasmussen, J. (2000). Human factors in a dynamic information society: where are we heading? Ergonomics, 43(7), 869-879. https://doi.org/10.1080/001401300409071

Rasmussen, J., \& Svedung, I. (2000). Proactive Risk Management in a Dynamic Society. Karlstad, Sweden: Swedish Rescue Services Agency.

Reich, Y., Konda, S. L., Monarch, I. A., Levy, S. N., \& Subrahmanian, E. (1996). Varieties and issues of participation and design. Design Studies, 17(2), 165-180. https://doi.org/10.1016/0142-694X(95)00000-H

Rifkin, J. (2012). La troisième révolution industrielle : comment le pouvoir latéral va transformer l'énergie, l'économie et le monde, Paris, France: LLL Les Liens qui Libèrent.

Robert, J.-M., \& Brangier, E. (2009). What Is Prospective Ergonomics? A Reflection and a Position on the Future of Ergonomics. In B.-T. Karsh (Ed.), Ergonomics and Health Aspects of Work with Computers (pp. 162-169). Berlin, Allemagne: Springer Heidelberg. https://doi.org/10.1007/978-3-642-02731-4_19

Sperandio, J. C. (1996). L'Homme face aux changements du travail contemporain : réflexion sur le rôle des ergonomes. In J.-C., Sperandio (Ed), L'ergonomie face aux changements technologiques et organisationnels du travail humain (pp. 3-8). Toulouse, France: Octarès.

Sperandio, J.-C. (1988). L'Ergonomie du travail mental. Paris, France: Masson. 
Toft, M. B., Schuitema, G., \& Thøgersen, J. (2014). The Importance of Framing for Consumer Acceptance of the Smart Grid: A Comparative Study of Denmark, Norway and Switzerland. Energy Research \& Social Science, 3, 113-123. https://ssrn.com/abstract=2619067

Vicente, K. J. (1999). Cognitive Work Analysis: Toward safe, productive, and healthy computer-based work. Mahwah, NJ: Erlbaum. https://doi.org/10.1201/b12457

\section{Copyrights}

Copyright for this article is retained by the author(s), with first publication rights granted to the journal.

This is an open-access article distributed under the terms and conditions of the Creative Commons Attribution license (http://creativecommons.org/licenses/by/4.0/). 